\title{
Medicolegal Aspects of Mental Disorders: A Retrospective Study during the Period 2005-2010
}

\author{
Wafaa M. Abdel Moneim, Zaghloul Thabet Mohammed, Safaa M. George', and \\ Fahd Abdel Azeem Mohamed²
}

\author{
${ }^{1}$ Department of Forensic Medicine and Clinical Toxicology, Faculty of Medicine, Assiut University \\ ${ }^{2}$ Ministry of Justice \\ Assiut, Egypt \\ All rights reserved.
}

\begin{abstract}
The World is suffering from an increasing burden of mental disorders and a widening treatment gap; about 450 million people worldwide suffer from a mental disorder or behavioral disorders.

This study evaluate the size of the mental disorder problem in Assuit Governorate during the period from 2005 to 2010 through collection of cases of mental disorders files from archive of Assuit MedicoLegal Department of Ministry of Justice during the period from 2005 to 2010. Methods: Data of cases suffering from mental disorders was collected from the archive of Assiut Medico-Legal Department of Ministry of Justice during the period from 2005 - 2010. The collected data included number of mental disorders cases, age, sex, and residence, sociodemographic factors, type of complaint of the plaintiff, the common types of mental disorders, and types of the problems with mental disorders civil or criminal. Results: The total number of the cases with mental disorders in the period from 2005 to 2010 was 163 cases, the highest percent of mental disorders cases occurred in the year 2008 with a percent of $19,64 \%$ from all mental disorders cases during the period from 2005 to 2010 followed by the year 2009 with a percent of $19 \%$ while the lowest number of cases was in 2006 with a percent of $11.66 \%$. The highest frequency of mental disorders occurred in the middle age group from $20-<30$ years, with male predominance. Males represent about triple the number of females. The frequency of mental disorders was the highest in Assiut City (65) cases (39.88\%) while the least percentage was 2 cases (1.23 \%) in El Ghanaime. Most of the cases $(61.59 \%)$ had with primary mental disorders while only $(37.43 \%)$ had secondary mental disorders and both of them were more common in males. The Classification according to psychiatric consultants who contracting with the Assuit Medico-Legal Department of Ministry of Justice. The majority of cases (159 cases) in this study were presented with civil problems and only 4 cases were presented with criminal problems. Conclusion: the problem of mental disorder is considered one of the challenges that face the Egyptian community so all efforts must cooperate to eliminate and treat all the problems associated with it.
\end{abstract}

\section{Introduction}

Mental disorder is a legal term and an important category in the various mental health acts (John and Pamela, 1993). It is like any disease or condition affecting the brain that influences the way a person thinks, feels, behaves and/or relates to others and to his or her surroundings. Although the symptoms of a mental disorder can range from mild to severe and are different depending on the type of mental disorder, a person with an untreated mental disorder is unable to cope with life's daily routines and demands (Peck and Scheffler, 2002).

The recognition and understanding of mental health conditions have changed over time and across cultures, and there are still variations in the definition, assessment, and classification of mental disorders (Insel and Wang, 2010).

The definition and classification of mental disorders are key issues for mental health and for users and providers of mental health services. Most international clinical documents use the term "mental disorder". There are currently two widely established systems that classify mental disorders The International Classification of Diseases (ICD- 10), part of this classification produced by the World Health Organization (WHO), and the Diagnostic and Statistical Manual of Mental Disorders (DSM-IV) 
produced by the American Psychiatric Association (APA) (Clark, 2007).

The prevalence of mental disorders in Europe is about $14 \%$ of the population (Demyttenaere et al., 2004). In the United States, about $26.2 \%$ of Americans ageing 18 years and older (about one in four adults) suffer from a diagnosable mental disorder in a given year (Kessler et al., 2005).

In Egypt, it has been found that $16.93 \%$ of the adult population suffers from mental disorders. A National Survey of Prevalence of Mental Disorders in Egypt found that most common disorders were mood and anxiety disorders. The least common were alcohol or drug dependence and adjustment disorders (Carr, 2009).

The forensic expert may be asked to give his opinion on the state of mind of the accused at the time of the committed offence. He may be also asked to comment on the present state of the person awaiting trial. The forensic expert should be cautioned not to venture his opinion in the court of law without understanding the full implications of his opinion and the bearing it has on the social, legal and moral issues involved (Tirpude et al., 2006).

A forensic psychiatrist is asked to determine the responsibility of the person in committing a crime, or his fitness for trial in case of criminal proceedings. In case of civil proceedings, he evaluates the fitness of the person for performing all civil affairs. In some countries, general psychiatrists can practice forensic psychiatry as well (e.g. Egypt). Others require training of the general psychiatrists in forensic psychiatry. Some countries require a specific certification to do this type of work (e.g. Japan) (Bursztajn, 2007).

\section{Aim of the study}

This study has been designated to:

1- Assessment the cases of mental disorders in Assiut Governorate according to the number of cases referred to Assuit Medico-Legal department of ministry of Justice during the period from $2005-2010$.

2- Compare the cases of mental disorders among different age groups, and among different sexes.

3- Spotlight on some legal and civil problems associated with mental disorders.

4- Identification of the sociodemographic data of the persons with mental disorders and malingering with medicolegal problems.

\section{Subjects and methods}

This study is a retrospective study.

\section{Preparation of the study}

1- Communications with the personnel who could facilitate performing the practical part of the study, this included official approval for reviewing the medico-legal Department of Ministry of Justice at Assuit governorate in which the practical part of the study was done.

2- Analysis of the data

\section{Ethical consideration}

Ethical considerations were taken regarding the consent of the legal authorities and the confidentiality of the obtained data.

\section{Data collection and analysis}

Data of cases suffering from mental disorders was collected from the archive of Assiut Medico-Legal Department of Ministry of Justice during the period from $2005-2010$. The collected data included number of mental disorder cases, age, sex, and residence and sociodemographic data of the cases of mental disorders, type of complaint of the plaintiff, the common types of mental disorders, and types of the problems with mental disorders civil or criminal.

\section{Statistical analysis of data}

Data was verified, coded and statistically analyzed. Frequencies with number and percent and descriptive statistics with graphical presentation of the results were done.

\section{Results}

The results are summarized in the following tables and figures:

Table (1) reveals that the total number of cases of mental disorders in this period was 163 cases representing $0.04 \%$ of all cases.

The greatest number of cases was recorded in $2008(32)$ cases $(19.64 \%)$ and the least number was in 2006 (19 cases $11.65 \%$ )

Table (2) shows the distribution of cases suffering from mental disorders according to their different age groups and duration. The highest percentage of the cases was in the age group from 20 $<30$ years $(37.43 \%)$ then from $30-<40$ years $(29.45 \%)$ then from $40-50$ years $(16.57 \%)$ followed by $50-<60$ years $(7.37 \%)$ and above 60 years (3.68\%). While the lowest percentage of cases was observed from $10-<20$ years $(2.46 \%)$. The age ranged from 10 to $>60$ years

Figure (1) shows the distribution of cases suffering from mental disorders according to their sex per year. The highest number of males was in year 2008 (26 cases, 15.95\%) while the highest number of females were found in 2010 (10 cases, 6.14\%).

Table (3) shows the distribution of cases suffering from mental disorders according to their residence in the period from $2005-2010$. It reveals that the greatest percentage of cases was found in Assiut City (65 cases, 39.88\%) while the least percentage was (2 cases, $1.23 \%$ ) in El Ghanaiem

Table (4) shows the association of sociodemographic factors with mental disorders cases in men and women. It reveals that the majority of cases ware illiterate (126) cases while 110 cases were unskilled and no cases diagnosed as mental disorder among retired or unemployed and the majority of cases were single (126 cases) followed by married persons (27 cases).

Table (5) shows the distribution of cases suffering from mental disorders according to the diagnosis in the period from 2005-2010. The greatest 
number of cases suffering from primary mental disorders was found in 2005 and the least in 2006 while the greatest number of cases suffering from secondary mental disorders was found in 2007 and 2008 and the least in 2005. In addition, it reveals that males represented higher percentage than females of both primary and secondary mental disorders. It shows also that primary mental disorders exceeded secondary mental disorders in the studied cases.

Table (6) shows the distribution of the cases suffering from primary mental disorders according to the cause in the period from 2005-2010. The highest percentage of the cases was diagnosed as mongolism, followed by moron, imbecile, cretinism and idiot respectively.

Table (7) shows the distribution of the cases of primary mental disorders according to sex in the period from 2005-2010. Males represent a higher percentage of the cases than females during the years of the study

Table (8) shows the distribution of the cases suffering from secondary mental disorders according to the cause in the period form 2005-2010. The highest percentage of the cases was diagnosed as schizophrenia, followed by posttraumatic psychosis, malingering, dementia, and post infection respectively.

Table (9) shows the distribution of the cases of secondary mental disorders according to sex in the period from 2005-2010. Males represented the higher percentage of the cases than females during the period of study

Table (10) shows the distribution of the cases suffering from mental disorders according to the type of the problems civil or criminal in the period from 2005 - 2010. It reveals that most of the cases (159 cases) presented with civil problems and only 4 cases with criminal problems

Table (11) shows the distribution of the cases suffering from mental disorders according to the complaint of the plaintiff in the period from 2005 2010. It reveals that the most common complaint was eligibility for pension while custody of children was the least one.

Table (1): The annual frequency of the cases of mental disorders referred to Assuit Medico-Legal Department of Ministry of Justice in the period from 2005-2010.

\begin{tabular}{|l|c|c|c|}
\hline Year & No of all cases & No of cases of mental disorders & $(\mathbf{\%})$ \\
\hline 2005 & 586 & 25 & 0.05 \\
\hline 2006 & 721 & 19 & 0.03 \\
\hline 2007 & 706 & 27 & 0.04 \\
\hline 2008 & 892 & 32 & 0.04 \\
\hline 2009 & 972 & 31 & 0.04 \\
\hline 2010 & 1008 & 29 & 0.03 \\
\hline Total & 4885 & 163 & 0.04 \\
\hline
\end{tabular}

Table (2): The distribution of cases suffering from mental disorders according to age groups referred to Assuit Medico-Legal Department of Ministry of Justice in the period from 2005-2010.

\begin{tabular}{|c|c|c|c|c|c|c|c|c|}
\hline Age group & Year & 2005 & 2006 & 2007 & 2008 & 2009 & 2010 & Total \\
\hline \multirow[t]{2}{*}{$0-<10$ years } & No. & - & - & - & - & - & - & - \\
\hline & $\%$ & - & - & - & - & - & - & - \\
\hline \multirow[t]{2}{*}{$10<20$ years } & No. & - & - & - & - & 3 & 1 & 4 \\
\hline & $\%$ & - & - & - & - & 9.6 & 3.4 & 2.45 \\
\hline \multirow[t]{2}{*}{$20-<30$ years } & No. & 10 & 6 & 13 & 15 & 8 & 14 & 61 \\
\hline & $\%$ & 40 & 31 & 48 & 46.9 & 25.8 & 48.3 & 37.4 \\
\hline \multirow[t]{2}{*}{$30-<40$ years } & No. & 9 & 10 & 5 & 10 & 9 & 5 & 48 \\
\hline & $\%$ & 36 & 52 & 18.5 & 31.2 & 29 & 17.2 & 29.4 \\
\hline \multirow[t]{2}{*}{$40-<50$ years } & No. & 3 & 1 & 5 & 3 & 10 & 5 & 27 \\
\hline & $\%$ & 12 & 5.2 & 18.5 & 9.4 & 32.2 & 17.2 & 16.55 \\
\hline \multirow[t]{2}{*}{$50-<60$ years } & No. & 3 & 1 & 2 & 2 & 1 & 3 & 12 \\
\hline & $\%$ & 12 & 5.2 & 7.4 & 6.2 & 3.2 & 10.3 & 7.36 \\
\hline \multirow[t]{2}{*}{$>60$ years } & No. & - & 1 & 2 & 2 & - & 1 & 6 \\
\hline & $\%$ & - & 5.2 & 7.4 & 6.2 & - & 3.4 & 3.7 \\
\hline \multirow[t]{2}{*}{ Total } & No. & 25 & 19 & 27 & 32 & 31 & 29 & \multirow[t]{2}{*}{163} \\
\hline & $\%$ & 15.33 & 11.65 & 16.56 & 19.63 & 19 & 17.79 & \\
\hline
\end{tabular}


Table (3): The distribution of the cases suffering from mental disorders referred to Assuit Medico-Legal Department of Ministry of Justice according to their residence in the period from 2005-2010.

\begin{tabular}{|c|c|c|c|c|c|c|c|c|}
\hline Residence & Year & 2005 & 2006 & 2007 & 2008 & 2009 & 2010 & Total \\
\hline \multirow[t]{2}{*}{ Assiut City } & No. & 11 & 7 & 12 & 11 & 12 & 12 & 65 \\
\hline & $\%$ & 44.0 & 36.85 & 44.45 & 43.38 & 38.71 & 41.38 & 39.87 \\
\hline \multirow[t]{2}{*}{ Assiut's Center } & No. & 2 & 3 & 6 & 5 & 4 & 5 & 25 \\
\hline & $\%$ & 8 & 15.79 & 22.23 & 15.63 & 12.9 & 17.25 & 15.33 \\
\hline \multirow[t]{2}{*}{ Abnoub and Elfath } & No. & 2 & - & 2 & 1 & 1 & 3 & 9 \\
\hline & $\%$ & 8 & - & 7.41 & 3.13 & 3.23 & 10.35 & 15.33 \\
\hline \multirow[t]{2}{*}{ Sedfa } & No. & 2 & 1 & - & 2 & - & 1 & 6 \\
\hline & $\%$ & 8 & 5.27 & - & 6.25 & - & 3.45 & 3.68 \\
\hline \multirow[t]{2}{*}{ Abutieg } & No. & 2 & 1 & 1 & 2 & 3 & 1 & 10 \\
\hline & $\%$ & 8 & 5.27 & 3.71 & 6.25 & 9.68 & 3.45 & 6.1 \\
\hline \multirow[t]{2}{*}{ El-Badary } & No. & 2 & 1 & 1 & - & - & - & 5 \\
\hline & $\%$ & 8 & 5.27 & 3.71 & - & - & - & 3.0 \\
\hline \multirow[t]{2}{*}{ Sahel Selim } & No. & 1 & - & - & 1 & 1 & 2 & 5 \\
\hline & $\%$ & 4.0 & - & - & 3.23 & 3.23 & 6.9 & 3.0 \\
\hline \multirow[t]{2}{*}{ Manfalout } & No. & 2 & - & 1 & 2 & 2 & 1 & 8 \\
\hline & $\%$ & 8.0 & - & 3.71 & 6.25 & 6.46 & 3.45 & 4.9 \\
\hline \multirow[t]{2}{*}{ El-Quosia } & No. & - & 2 & 2 & 3 & 2 & 1 & 10 \\
\hline & $\%$ & - & 10.54 & 7.41 & 9.34 & 6.46 & 3.45 & 6.1 \\
\hline \multirow[t]{2}{*}{ Dayrout } & No. & 1 & 3 & 2 & 4 & 6 & 2 & 18 \\
\hline & $\%$ & 4.0 & 15.79 & 7.41 & 12.5 & 19.36 & 6.9 & 11.0 \\
\hline \multirow[t]{2}{*}{ El-Ghanaime } & No. & - & - & - & 1 & - & 1 & 2 \\
\hline & $\%$ & - & - & - & 3.13 & - & 3.45 & 1.23 \\
\hline \multirow[t]{2}{*}{ Total } & No. & 25 & 19 & 27 & 32 & 31 & 29 & \multirow[t]{2}{*}{163} \\
\hline & $\%$ & 15.33 & 11.65 & 15.56 & 19.63 & 19.0 & 17.79 & \\
\hline
\end{tabular}

Table (4): Association of sociodemograpic factors with the mental disorder cases referred to Assuit Medico-Legal Department of Ministry of Justice cases in males and females in the period from 2005-2010.

\begin{tabular}{|c|c|c|c|c|c|c|c|c|c|c|c|c|c|}
\hline \multirow{2}{*}{$\begin{array}{c}\text { Year } \\
\text { Variable }\end{array}$} & \multicolumn{2}{|c|}{2005} & \multicolumn{2}{|c|}{2006} & \multicolumn{2}{|c|}{2007} & \multicolumn{2}{|c|}{2008} & \multicolumn{2}{|c|}{2009} & \multicolumn{2}{|c|}{2010} & \multirow{2}{*}{ Total } \\
\hline & $\mathbf{M}$ & $\mathbf{F}$ & $\mathbf{M}$ & $\mathbf{F}$ & $\mathbf{M}$ & $\mathbf{F}$ & $\mathbf{M}$ & $\mathbf{F}$ & $\mathbf{M}$ & $\mathbf{F}$ & $\mathbf{M}$ & $\mathbf{F}$ & \\
\hline Education & \multirow[t]{2}{*}{18} & \multirow[t]{2}{*}{4} & \multirow[t]{2}{*}{12} & \multirow[t]{2}{*}{3} & \multirow[t]{2}{*}{14} & \multirow[t]{2}{*}{6} & \multirow[t]{2}{*}{16} & \multirow[t]{2}{*}{6} & \multirow[t]{2}{*}{14} & \multirow[t]{2}{*}{6} & \multirow[t]{2}{*}{17} & \multirow[t]{2}{*}{10} & \multirow[t]{2}{*}{126} \\
\hline Not Educated & & & & & & & & & & & & & \\
\hline Below secondary & - & - & 1 & - & 4 & - & 1 & - & 2 & 2 & 2 & - & 12 \\
\hline Secondary & 3 & - & 1 & 1 & 2 & 1 & 7 & - & 5 & 1 & - & - & 21 \\
\hline University & - & - & 1 & - & - & - & 2 & - & 1 & - & - & - & 4 \\
\hline Occupation: Professional & 1 & - & 1 & - & 1 & - & 3 & - & 4 & - & - & - & 10 \\
\hline House wife & - & 2 & - & 2 & - & 4 & - & 3 & - & 3 & - & 1 & 15 \\
\hline Skilled & 4 & - & 3 & - & 5 & - & 5 & - & 3 & 1 & 7 & - & 28 \\
\hline Unskilled & 16 & 2 & 11 & 2 & 14 & 3 & 18 & 3 & 14 & 6 & 12 & 9 & 110 \\
\hline Retired & - & - & - & - & - & - & - & - & - & - & - & - & - \\
\hline Unemployed & - & - & - & - & - & - & - & - & - & - & - & - & - \\
\hline Marital status: Married & 1 & - & 3 & 1 & 4 & 3 & 6 & 1 & 3 & 1 & 3 & 1 & 27 \\
\hline Divorced & - & 1 & - & - & - & - & - & - & - & - & - & - & 1 \\
\hline Widowed & - & - & - & 1 & 1 & 1 & - & 2 & 1 & - & 1 & - & 7 \\
\hline Single & 20 & 3 & 12 & 2 & 15 & 3 & 20 & 3 & 15 & 9 & 15 & 9 & 126 \\
\hline
\end{tabular}

M: Male; F: Female 
Table (5): The distribution of the cases suffering from mental disorders referred to Assuit Medico-Legal Department of Ministry of Justice according to the diagnosis and sex in the period from 2005-2010.

\begin{tabular}{|c|c|c|c|c|c|c|c|c|c|}
\hline \multirow{3}{*}{$\underbrace{\text { Diagnosis and sex }}_{\text {Year }}$} & \multicolumn{4}{|c|}{ Primary mental disorders* } & \multicolumn{4}{|c|}{ Secondary mental disorders } & \multirow{3}{*}{ Tota } \\
\hline & \multicolumn{2}{|c|}{ Male } & \multicolumn{2}{|c|}{ Female } & \multicolumn{2}{|c|}{ Male } & \multicolumn{2}{|c|}{ Female } & \\
\hline & No. & $\%$ & No. & $\%$ & No. & $\%$ & No. & $\%$ & \\
\hline 2005 & 18 & 72 & 2 & 8 & 3 & 12 & 2 & 8 & 25 \\
\hline 2006 & 11 & 57.9 & 2 & 10.53 & 4 & 21.06 & 2 & 10.53 & 19 \\
\hline 2007 & 14 & 51.86 & 4 & 12.5 & 13 & 40.63 & 4 & 12.5 & 32 \\
\hline 2008 & 11 & 34.38 & 4 & 12.5 & 13 & 40.63 & 4 & 12.5 & 32 \\
\hline 2009 & 13 & 41.94 & 5 & 16.13 & 8 & 25.81 & 5 & 16.13 & 31 \\
\hline 2010 & 11 & 37.94 & 8 & 27.59 & 7 & 24.14 & 3 & 10.35 & 29 \\
\hline Total & 78 & 47.86 & 24 & 14.73 & 41 & 25.16 & 20 & 12.27 & 163 \\
\hline
\end{tabular}

* The Classification was done according to the psychiatric consultants who were working for the Assuit Medico-Legal

Department of Ministry of Justice.

Table (6): The distribution of the cases suffering from primary mental disorders referred to Assuit Medico-Legal Department of Ministry of Justice according to the cause in the period from 2005-2010.

\begin{tabular}{|c|c|c|c|c|c|c|c|c|c|c|c|c|c|c|}
\hline Year & \multicolumn{2}{|c|}{2005} & \multicolumn{2}{|c|}{2006} & \multicolumn{2}{|c|}{2007} & \multicolumn{2}{|c|}{2008} & \multicolumn{2}{|c|}{2009} & \multicolumn{2}{|c|}{2010} & \multicolumn{2}{|c|}{ Total } \\
\hline Cause & No. & $\%$ & No. & $\%$ & No. & $\%$ & No. & $\%$ & No. & $\%$ & No. & $\%$ & No. & $\%$ \\
\hline Mongolism & 6 & 13.6 & 7 & 15.9 & 9 & 20.5 & 6 & 13.7 & 9 & 20.5 & 7 & 15.9 & 44 & 43.1 \\
\hline Cretinism & 2 & 15.4 & 1 & 7.7 & 3 & 23.0 & 3 & 23.0 & 2 & 15.4 & 2 & 15.4 & 13 & 12.8 \\
\hline Moron & 5 & 21.7 & 3 & 13.1 & 3 & 13.1 & 4 & 17.4 & 2 & 8.7 & 6 & 26.1 & 23 & 22.6 \\
\hline Imbecile & 3 & 20.0 & 1 & 6.67 & 1 & 6.67 & 1 & 6.67 & 5 & 33.3 & 4 & 26.7 & 15 & 14.7 \\
\hline Idiot & 4 & 57.2 & 1 & 14.3 & 1 & 14.3 & 1 & 14.3 & - & - & - & - & 7 & 6.87 \\
\hline Total & 20 & 19.6 & 13 & 12.8 & 14 & 13.7 & 15 & 14.7 & 18 & 17.7 & 19 & 18.6 & & \\
\hline
\end{tabular}

Table (7): The distribution of the cases of primary mental disorders referred to Assuit Medico-Legal Department of Ministry of Justice according to sex in the period from $2005-2010$.

\begin{tabular}{|c|c|c|c|c|c|c|c|c|c|c|c|c|c|}
\hline \multirow{2}{*}{ Cause } & \multicolumn{2}{|c|}{2005} & \multicolumn{2}{|c|}{2006} & \multicolumn{2}{|c|}{2007} & \multicolumn{2}{|c|}{2008} & \multicolumn{2}{|c|}{2009} & \multicolumn{2}{|c|}{2010} & \multirow{2}{*}{ Tota } \\
\hline & $\mathbf{M}$ & $\mathbf{F}$ & $\mathbf{M}$ & $\mathbf{F}$ & $\mathbf{M}$ & $\mathbf{F}$ & $\mathbf{M}$ & $\mathbf{F}$ & $\mathbf{M}$ & $\mathbf{F}$ & $\mathbf{M}$ & $\mathbf{F}$ & \\
\hline Mongolism & 5 & 1 & 6 & 1 & 8 & 1 & 4 & 2 & 7 & 2 & 4 & 3 & 44 \\
\hline Cretinism & 2 & - & 1 & - & 1 & 2 & 2 & 1 & 1 & 1 & 1 & 1 & 13 \\
\hline Moron & 4 & 1 & 3 & - & 3 & - & 4 & - & 1 & 1 & 3 & 3 & 23 \\
\hline Imbecile & 3 & - & - & 1 & 1 & - & - & 1 & 4 & 1 & 3 & 1 & 15 \\
\hline Idiot & 4 & - & 1 & - & 1 & - & 1 & - & - & - & - & - & 7 \\
\hline Total & 18 & 2 & 11 & 2 & 14 & 3 & 11 & 4 & 13 & 5 & 11 & 8 & 102 \\
\hline
\end{tabular}

M: Male; F: Female

Table (8): The distribution of the cases suffering from secondary mental disorders referred to Assuit MedicoLegal Department of Ministry of Justice according to the cause in the period form 2005-2010.

\begin{tabular}{|c|c|c|c|c|c|c|c|c|c|c|c|c|c|c|}
\hline \multirow{2}{*}{ Cause $\quad$ Year } & \multicolumn{2}{|c|}{2005} & \multicolumn{2}{|c|}{2006} & \multicolumn{2}{|c|}{2007} & \multicolumn{2}{|c|}{2008} & \multicolumn{2}{|c|}{2009} & \multicolumn{2}{|c|}{2010} & \multicolumn{2}{|c|}{ Total } \\
\hline & No. & $\%$ & No. & $\%$ & No. & $\%$ & No. & $\%$ & No. & $\%$ & No. & $\%$ & No. & $\%$ \\
\hline Schizophrenia & 4 & 9.8 & 2 & 4.9 & 6 & 14.6 & 10 & 24.4 & 9 & 22.0 & 10 & 24.4 & 41 & 67.2 \\
\hline Malingering & - & - & - & - & - & - & 3 & 60.0 & 2 & 40.0 & - & - & 5 & 8.2 \\
\hline Post-traumatic psychosi & 1 & 14.3 & 1 & 14.3 & 2 & 28.6 & 1 & 14.3 & 2 & 28.6 & - & - & 7 & 11.5 \\
\hline Dementia & - & - & 1 & 25.0 & 2 & 50.0 & 1 & 25.0 & - & - & - & - & 4 & 6.6 \\
\hline Post-infection & - & - & 2 & 50.0 & - & - & 2 & 50.0 & - & - & - & - & 4 & 6.6 \\
\hline Total & 5 & 8.2 & 6 & 9.8 & 10 & 16.4 & 17 & 27.9 & 13 & 21.3 & 10 & 16.4 & & \\
\hline
\end{tabular}

Table (9): The distribution of the cases suffering secondary mental disorders referred to Assuit Medico-Legal Department of Ministry of Justice according to sex in the period from 2005-2010.

\begin{tabular}{|c|c|c|c|c|c|c|c|c|c|c|c|c|c|}
\hline \multirow{2}{*}{ Cause Year and Sex } & \multicolumn{2}{|c|}{2005} & \multicolumn{2}{|c|}{2006} & \multicolumn{2}{|c|}{2007} & \multicolumn{2}{|c|}{2008} & \multicolumn{2}{|c|}{2009} & \multicolumn{2}{|c|}{2010} & \multirow{2}{*}{ Total } \\
\hline & $\mathbf{M}$ & $\mathbf{F}$ & $\mathbf{M}$ & $\mathbf{F}$ & $\bar{M}$ & $\mathbf{F}$ & $\mathbf{M}$ & $\mathbf{F}$ & $\mathbf{M}$ & $\mathbf{F}$ & $\mathbf{M}$ & $\mathbf{F}$ & \\
\hline Schizophrenia & 2 & 2 & 1 & 1 & 3 & 3 & 8 & 2 & 5 & 4 & 7 & 3 & 41 \\
\hline Malingering & - & - & - & - & - & - & 2 & 1 & 1 & 1 & - & - & 5 \\
\hline Post-traumatic psychosis & 1 & - & 1 & - & 2 & - & 1 & - & 2 & - & - & - & 7 \\
\hline Dementia & - & - & - & 1 & 1 & 1 & - & 1 & - & - & - & - & 4 \\
\hline Post-infection & - & - & 2 & - & - & - & 2 & - & - & - & - & - & 4 \\
\hline Total & 3 & 2 & 4 & 2 & 6 & 4 & 13 & 4 & 8 & 5 & 7 & 3 & 61 \\
\hline
\end{tabular}

M: Male; F: Female 
Table (10): The distribution of the cases suffering from mental disorders referred to Assuit Medico-Legal Department of Ministry of Justice according to the type of the problems civil or criminal in the period from $2005-2010$.

\begin{tabular}{|l|c|c|c|c|c|c|c|}
\hline $\begin{array}{r}\text { Year } \\
\text { Type of problems }\end{array}$ & $\mathbf{2 0 0 5}$ & $\mathbf{2 0 0 6}$ & $\mathbf{2 0 0 7}$ & $\mathbf{2 0 0 8}$ & $\mathbf{2 0 0 9}$ & $\mathbf{2 0 1 0}$ & Total \\
\hline Civil problems & $25(16 \%)$ & $19(12 \%)$ & $27(17 \%)$ & $29(18 \%)$ & $30(19 \%)$ & $29(18 \%)$ & $159(97.5 \%)$ \\
\hline Criminal problems & $-(0 \%)$ & $-(0 \%)$ & $-(0 \%)$ & $3(75 \%)$ & $1(25 \%)$ & $-(0 \%)$ & $4(2.5 \%)$ \\
\hline Total & $25(15.3 \%)$ & $19(11.7 \%)$ & $27(16.5 \%)$ & $32(19.6 \%)$ & $31(19 \%)$ & $29(17.9 \%)$ & $163(100 \%)$ \\
\hline
\end{tabular}

Table (11): The distribution of the cases suffering from mental disorders referred to the Assuit Medico-Legal Department of Ministry of Justice according to the complaint of the plaintiff in the period from $2005-2010$.

\begin{tabular}{|c|c|c|c|c|c|c|c|c|c|c|c|c|c|c|}
\hline \multirow{2}{*}{$\begin{array}{ll}\text { Complaint } & \text { Year }\end{array}$} & \multicolumn{2}{|c|}{2005} & \multicolumn{2}{|c|}{2006} & \multicolumn{2}{|c|}{2007} & \multicolumn{2}{|c|}{2008} & \multicolumn{2}{|c|}{2009} & \multicolumn{2}{|c|}{2010} & \multicolumn{2}{|c|}{ Total } \\
\hline & No. & $\%$ & No. & $\%$ & No. & $\%$ & No. & $\%$ & No. & $\%$ & No. & $\%$ & No. & $\%$ \\
\hline Eligibility for pension & 14 & 20.9 & 10 & 14.9 & 8 & 11.9 & 11 & 16.4 & 13 & 19.4 & 11 & 16.4 & 67 & 41.1 \\
\hline Heritage & 7 & 18.4 & 3 & 7.9 & 4 & 10.5 & 9 & 23.7 & 5 & 13.2 & 10 & 26.3 & 38 & 23.3 \\
\hline Management of funds & 4 & 8.3 & 4 & 8.3 & 10 & 20.8 & 12 & 25.0 & 10 & 20.8 & 8 & 16.7 & 48 & 29.5 \\
\hline Divorce & - & - & 1 & 14.3 & 4 & 57.2 & - & - & 2 & 28.6 & - & - & 7 & 4.3 \\
\hline Custody of children & - & - & 1 & 33.3 & 1 & 33.3 & - & - & 1 & 33.3 & - & - & 3 & 1.8 \\
\hline Total & 25 & 15.3 & 19 & 11.7 & 27 & 16.6 & 32 & 19.6 & 31 & 19.0 & 29 & 17.8 & & \\
\hline
\end{tabular}

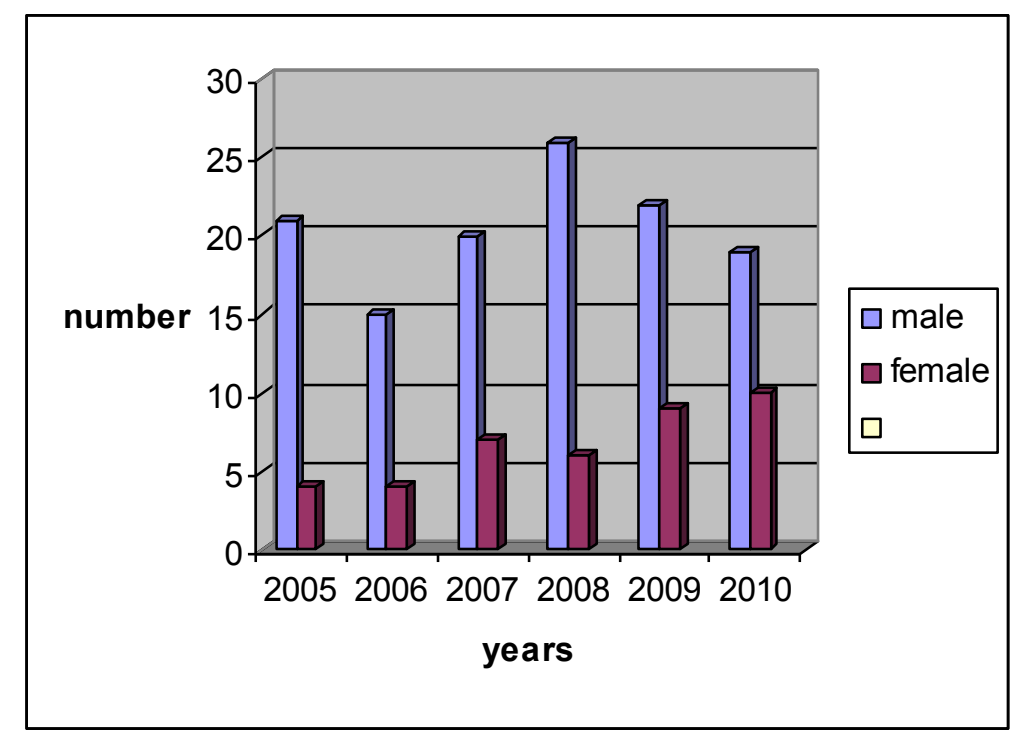

Fig (1): The distribution of the cases suffering from mental disorders according to their sex referred to Assuit Medico-Legal Department of Ministry of Justice in the period from 2005-2010.

\section{Discussion}

The World is suffering from an increasing burden of mental disorder and a widening treatment gap; about 450 million people worldwide suffer from a mental disorder or behavioral disorder, yet only a small minority receives even the most basic treatment. Mental disorder cases are likely to increase due to ageing of the population and deterioration in infrastructure and public health services (Bulletin of the World Health Organization, 2000).

Although surveys of mental disorders have been carried out since the end of World War II, little is known about the extent or severity of untreated mental disorders, especially in developing countries like Egypt. Health care delivery in Egypt still faces many problems. Both facilities and staff tend to be unevenly distributed, clustering mainly in urban areas, such as Cairo and Alexandria. The total number of available beds for psychiatric cases is inadequate: less than 10 000 beds, around 13 per 100000 populations. The number of professionals specialized in mental health is far below international standards. The main obstacle facing the services, however, is that they are hospitalbased rather than community-based (Ghanem, 2004).

The current study aimed to evaluate the size of the problem of mental disorders referred to the medicolegal authorities in Assiut Governorate during the period from 2005-2010, list of the most common types of mental disorders and estimation of the prevalence of legal and civil problems among cases suffering from mental disorders. Meanwhile to provide a set of recommendations to decrease the problems associated with mental disorders

The total prevalence of mental disorder cases among population in Assiut Governorate (163 cases) 
was, 0.4\%. In Egypt, Ghanem et al., (2009) found the prevalence $16.93 \%$ while Noorbala et al., (2004) did a survey in Iran in which the prevalence was $21 \%$. This difference may be explained by that Ghanem did his survey on five areas in Egypt. Prevalence was generally lower than corresponding European figures. The rate of prevalence varies a lot among different countries especially among children depending on diagnostic systems, the age of the child, and source of the administrative data; for example, using clinical guide lines based on more comprehensive adaptive behavior and psychological assessment (King et al., 2009).

In developing countries, most studies are based on clinical assessment, making it difficult to compare such studies with each other. Using a simple set of questions followed by clinical evaluation, Stein et al., (1987) found that the prevalence of mental retardation (IQ < 70) among 3-9 years old in eight developing countries (including some populous countries like India, Brazil, Bangladesh, and Pakistan) varied from 911000 in Pilippines to 15611000 in Bangladesh.

In this study the highest percentage of mental disorders occurred in the year 2008 (19.64 \%) followed by the year 2009 with a percent of $(19 \%)$ while the least percentage was in $2006(11.66 \%)$. This indicates that the problem of mental disorders shows an upward trend. This increase may be a result of the poorer health services, which may be reflected in the greater numbers of undiscovered and /or untreated cases.

Regarding the relationship between the age and mental disorders, it was found that the highest frequency of mental disorders occurred in the age group from $20-<30$ years with a percent of (37-43\%), while the least percentage was from $10-<20$ years $26.46 \%$.Mental disorder cases are likely to decrease in young age because of ageing and deterioration in infrastructure.

Child and adolescent psychiatry sometimes uses specific manuals in addition to the DSM and ICD. The Diagnostic Classification of Mental Health and Developmental Disorders of Infancy and Early Childhood (DC: 0-3) classified mental health and developmental disorders in the first four years of life. It has been published in nine languages (Alicia et al., 1997).

The French Classification of Child and Adolescent Mental Disorders, operational since 1983, is the classification of reference for French child psychiatrists (Mises et al., 2002).

As regards the relationship between sex and mental disorders, it was found that the frequency of mental disorders in males was nearly triple that of females $(75.46 \%$ in males compared to $24.54 \%$ in females). In contrast, Ghanem (2004) reported that women with mental disorders were over 2 times higher than men and they explained this finding by that women bear the burnt of the adversities associated with poverty: less access to education, physical abuse from husband, forced marriage, fewer job opportunities and, in some societies, limitation of participation in activities outside the house. Bijl et al., (1998) in their study in Netherland found that women had higher prevalence rates of mood and anxiety disorders than men, which is consistent with earlier epidemiologic studies. Men had higher rates of alcohol and drug abuse but there were no gender differences when all disorders were taken together.

In this study, males were more than females because the risk factors for mental disorders were similar for both men and women with the exception of occupation and smoking, these increased the risk of mental disorders in men and this may have been because the majority of the women in this study were housewives. In addition, differences in lifestyle and ability to tolerate stress of the work may also result in increased risk of mental disorders in some persons (Tirpude et al., 2006).

The frequency of mental disorders was higher in Assiut City (65 cases, $39.88 \%$ ) while the least percentage was 2 cases $(1.23 \%)$ in El Ghanaime. In contrast, Mumford et al., (2000) reported in their study that higher prevalence rate of mental disorders was found in the rural populations in Pakistan. Also, an early study in Egypt showed that depressive disorders were more prevalent in rural residents (Okasha et al., 1988). The result of this study agreed with Canino et al., (1987) who found in Latin America lower rates in rural villages than in urban areas. However, in a similar study in the Islamic Republic of Iran, the authors assured in their study that no difference was found between urban and rural areas. This may be because due to many rural residents migrate to urban areas and this may create two matching communities with same socioeconomic standards; consequently the urban-rural difference found by others may be masked. Both rural and urban residents have specific problems, however and this may also contribute to mask the difference. For instance, in urban areas, over crowding, polluted environment and high levels of violence may affect the rates of mental disorders. Rural residents may face problems such as lack of proper infrastructure and low socioeconomic standards (Noorbala et al., 2004).

The mental disorders were found among illiterate 126 cases and this is also in agreement with Noorbala et al., (2004) that carried out their study in Iran and concluded that with increasing educational level the risk of mental disorders decreases.

As regarding the relationship between occupation and mental disorders, it was found that mental disorders were more common in unskilled (110) cases followed by skilled (28 cases) and no cases among retired or unemployed. In contrast Hodiamont et al (1987), Behar et al. (1992), Murthy and Burns (1992), Stansfeld and Marmat (1992), and Noorbala et al (1998) found higher rates of mental disorders among housewives and unemployed persons.

In this study the frequency of mental disorders was more common in single (126 cases) than married 
persons (27 cases) and this may be explained by limited social relations and monotonous lifestyle. In contrast to Noorbala et al. (2004) who found in their surveys in Iran higher prevalence rates of mental disorders among the married.

Most of cases $102(61.59 \%)$ had primary mental disorders and 61 cases $(37.43 \%)$ had secondary mental disorders and both of them were more common in males. The majority of primary cases of mental disorders was diagnosed as Mongolism (44 cases) followed by Moron (23 cases) and Idiot was the least number of cases (7) and all of them were more common in males. In contrast to studies from area such as USA, Europe, Lebanon and Japan that revealed that mood and anxiety disorders were the commonest disorders reported (WHO, 2004). Also, Carr in (2009) did national survey on mental disorders in Egypt and found that most common disorders were mood and anxiety disorders. The least common disorders detected in the survey were alcohol or drug dependence and adjustment disorder.

As regarding secondary mental disorders the majority of cases were diagnosed as Schizophrenia $(67.2 \%)$ and the least number as Dementia and PostInfection $(6.6 \%)$ for each one. Schizophrenia is the most common disorder and this may be explained by that it is the most common psychosis in Egypt and accounts for the majority of in-patients in mental hospitals (Okasha et al., 1993). Secondary mental disorders were higher in 2008 (17 cases) than in 2005 (five cases). This is in agreement with (Ghanem et al.,2009) who studied in selected regions (Alexandria, Giza, Qaliubia, Fayoum and Ismailia ) and found that psychiatric disorders represented only in $0.19 \%$ which is less than what has been reported from Dubai $(0.7 \%)$ ( Abou-Saleh et al., 2004 ). The low figure may be the result of the stigma related to that disorder.

About the problem of mental disorders, it was found that the majority of cases (159 cases) presented with civil problems and only four cases with criminal problems. This may be explained by that there are many civil problems associated with mental disorders as management of property and affairs of insane, illegal detention, insanity and contract, insanity and marriage contract, the competence of insane to be a witness, and insanity and testamentary capacity and these problems forced the people to complain (Tirpude et al., 2006).

In this study, no problems were found associated with alcohol or drug dependence. This is also in agreement with Ghanem et al., (2009) who found that the least common disorders indicated in their survey were alcohol or drug dependence.

In contrast ,Okasha, (1996) mentioned that the 1980s witnessed a sharp rise in morbidity due to drug misuse, since then, Egyptian community leaders at all levels have demonstrated intense concern over this problem.

Although epidemiological data on drug misuse in Egypt are scarce, health professionals report a multiple of reasons for such concern, including an increase in the rate of addicts seeking psychiatric treatment (Al Azayem and Ez Eldin, 1996), and alarming drop in age at initiation of drug use, with a consequent rise in adolescent addicts (Amer et al, 1986).

\section{Conclusion}

The problem of mental disorder is considered one of the challenges that face the Egyptian community so all efforts must cooperate to eliminate and treat all the problems associated with it.

\section{Recommendations}

Regular statistics and collection of all data and information should be done about the cases of mental disorders in our country to know the size of the problem of mental disorders, as community surveys in the field of psychiatry because such informations as a base for future mental health planning, development, training and incorporation of mental health in primary health care. The forensic expert should caution if he asked to determine the responsibility of the person in committing a crime, or his fitness for trial in case of criminal proceeding. In case of civil proceeding, he evaluates the fitness of the person for performing all civil affairs, further analysis of these risk factors to contribute towards primary prevention of mental illness in our culture.

\section{References}

Abou-Saleh MT, Ghubash R, and Daradkeh TK (2004): Al Ain community psychiatric survey. I: Prevalence and socio-demographic correlates. Social psychiatry and psychiatric epidemiology, 36(1): p 20-8.

Amer H, Saleh H, Guirguis W et al., (1986): Use of Delphi technique in determining certain factors related to drug dependence among youth Part I. Bulletin of the High Institute of Public Health, 16: p 63-77.

Al Azayem A and Ez Eldin A G (1996): Changing pattern of substance abuse and its reflection on management programs. Proceeding of First Egyptian International Conference on Addiction and Drug Abuse. Cairo: Ministry of Health.

Alicia F,Liebeman A, Serena W et al., (1997): Diagnostic classification: 0-3: Diagnostic classification of mental health and developmental disorders in infancy and early childhood. Washington, DC Building Strong Foundations, Practical Guidance for Promoting the Social-Emotional Development of Infants and Toddlers. Washington: ZERO TO THREE Press. Journal of the American Academy of Child and Adolescent Psychiatry | June 1, 1997 
Behar E, Henderson A S and Mackinnon A J (1992): An epidemiological study of mental health and socioeconomic conditions in Sumatra, Indonesia. Acta Psychiatrica Scandinavica, 85, 257- 263.

Bijl RV, Ravelli A and Zessan G (1998): Prevalence of Psychiatric disorder in the general population: results of the Netherland Mental Health Survey and Incidence Study (NEMESIS) Soc Psychiatry Epidemiol 33: p 587-595.

Bulletin of the World Health Organization (2000): Cross-national comparisons of the prevalence and correlates of mental disorders WHO international consortium in psychiatric epidemiology, 78(4): p 413-26.

Bursztajn H J (2007): The Role of a Forensic Psychiatrist in Legal Proceedings. Cited in www.forensicpsych.com/articles/artAskex01.php

Canino GJ, Bird HR and Shrout P E (1987): The prevalence of specific psychiatric disorders in Puerto Rico. Archives of general psychiatry, 44(8): p 727-5.

Carr S (2009):16 pct of Egyptians suffer mental illness. Cited in www.thedailynewsegypt.com visited in 4/8/2010.

Clark LA (2007): "Assessment and diagnosis of personality disorder: perennial issues and an emerging reconceptualization" Annu Rev Psychol 58: p 227-57.

Demyttenaere K, Alonso J and Bernert S (2004): Prevalence of mental disorders in Europe in Acta Psychiatrica Scandinavica.vol 109: p 2127.

Ghanem M (2004): Psychiatric services and activities in the Ministry of Health and Population. Journal of the Egyptian Psychiatric Association, 23(2): p 16-9.

Ghanem M, Gadallah M, Meky FA et al., (2009): National Survey of Prevalence of Mental Disorders in some governorates in Egypt: preliminary survey, Eastern Mediterranean Health Journal, Vol. 15, No 1: p 5-12.

Hodiamont P, Peer N and Syben N (1987): Epidemiological aspects of psychiatric disorder in a Dutch health area. Psychological Medicine, 17, 227-241.

Insel TR and Wang PS (2010): "Rethinking mental illness". JAMA 303 (19): p 1970-1971.

John G and Pamela JT (1993): Forensic Psychiatry Clinical, Legal and Ethical issues, $1^{\text {st }}$ Edition, Addictions and Dependencies; their Association with Offending: p 435-89.

Kessler RC, Chiu WT, Demler O et al., (2005): Prevalence, severity and comorbidity of twelve-month DSM-a Replication (NCSR).Archives of General Psychiatry;62(6): $p$ 617-27.

King BH, Toth KE, Hodapp RM et al., (2009): Intellectual Disability- In: Bj Sadock, V A
Sadock, P Ruiz, editors. Comprehensive Textbook of Psychiatry. $9^{\text {th }}$ ed. Philadelphia: Lippincott Williams and Wilkins: p 34443474.

Mises R, Quemada N, Botbol M et al., (2002): "French classification for child and adolescent mental disorders". Psychopathology 35 (2-3): p 17680 .

Mumford DB, Minhas F A, Akhtar I et al., (2000): Stress and psychiatric disorder in urban Rawalpindi, Acommunity survey.British journal of psychiatry, 177: p 557-62

Murthy R S and Burns N (1992): Community Mental Health Bangalore: National Institute of Mental Health and Neuroscience (NIHMANS) Publications.

Noorbala A A, Mohammad K, and Bagheri Yazdi S A (1998): A survey of psychiatric disorders in Tehran city. Hakim Magazine, 4, 212- 223.

Noorbala AA, Bagheri Yazdi SA, Yasamy MT et al., (2004): Mental health survey of the adult population in Iran. British journal of psychiatry, 184: p 70-3.

Okasha A (1996): Combat and management of drug abuse means and challenges. An Egyptian perspective. In: Proceeding of the first Egyptian international conference on addiction and drug abuse. Cairo. Ministry of Health. British journal of psychiatry

Okasha A, Khalil A H, El Fiky M R et al., (1988): Prevalence of depressive disorders in a sample of rural and urban Egyptian communities. Egyptian journal of psychiatry, 11: p 167-81.

Okasha A, Seif El Dawla A, Khalil AH et al., (1993): Presentation of acute psychosis in an Egyptian sample a transcultural comparison. Comprehensive psychiatry 1: p 155-159.

Peck MC and Scheffler RM (2002): "An analysis of the definitions of mental illness used in state parity laws".Psychiatr Ser 53 (9): p 1089-95.

Stansfeld S A and Marmat M G (1992): Social class and minor psychiatric disorder in British civil servants: a validated screening survey using the General Health Questionnaire. Psychological Medicine, 22, 739- 749.

Stein Z, Belmant Land Durkin m (1987): Mild mental retardation and sever mental retardation compared: Experiences in eight less developed countries. Upsala Journal of Medical Science Supp 44: p 89-96.

Tirpude BH, Sheikh NA and Chaudhary BL (2006): Medico-legal Update Psychiatry and Civil Law, Vol.6, No.4: p 10-12.

WHO "world health organization" World Mental Health Consortium, (2004): Prevalence, severity, and unmet need for treatment of mental disorders in the World Health Organization World Mental Health Surveys. Journal of the American Medical association, 291(21): p 2581-90. 
الملخص العزبي

الوجهة الطبية الشرعية للاضطرابات العقلية من في أسيوط: دراسة مرجعية في الفترة من

وفاء محمد عبد المنعم و زغلول ثابت محمد و صفاء ماهر جورج و فهـ عبد العظيم محمد2

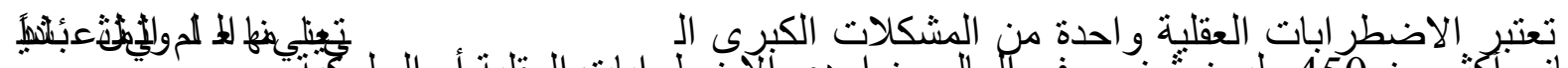

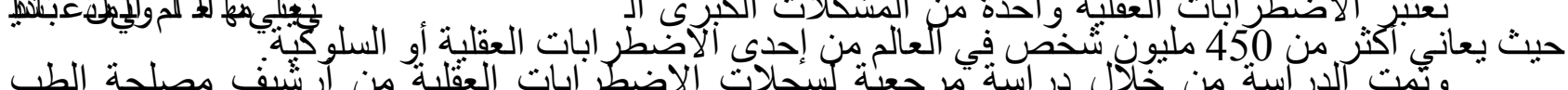

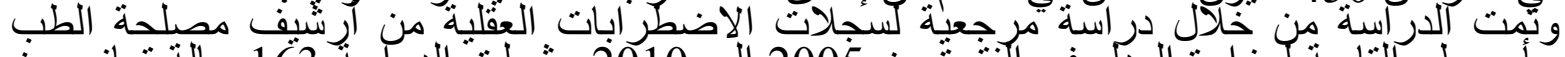

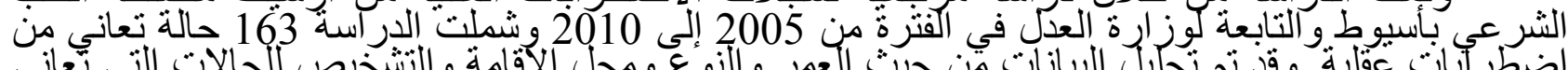

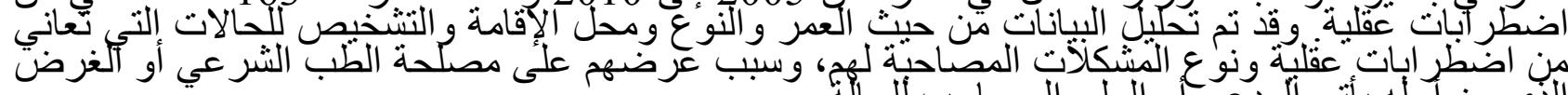

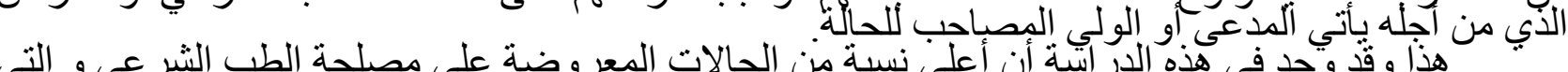

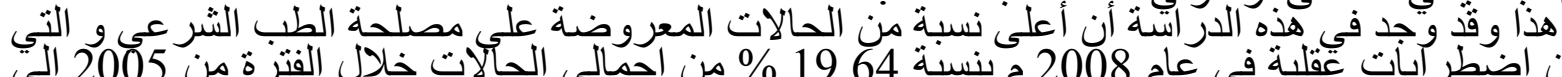

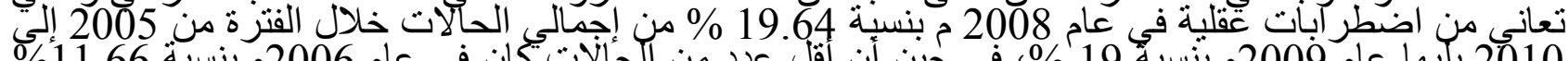

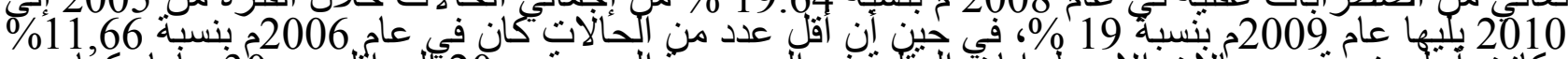

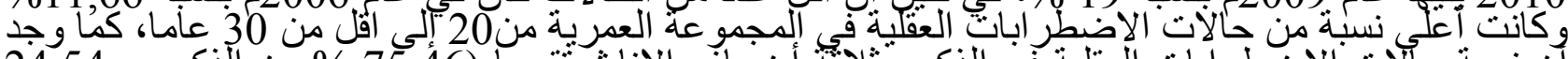

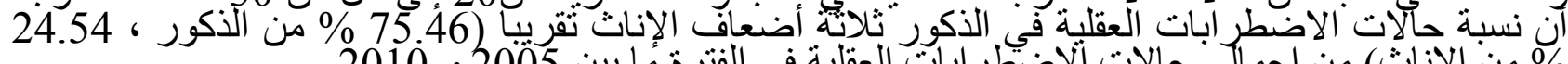

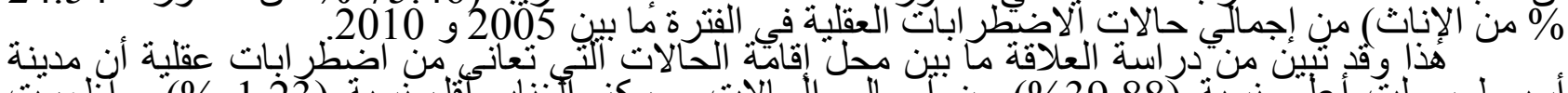

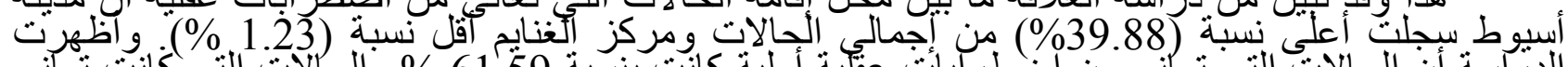

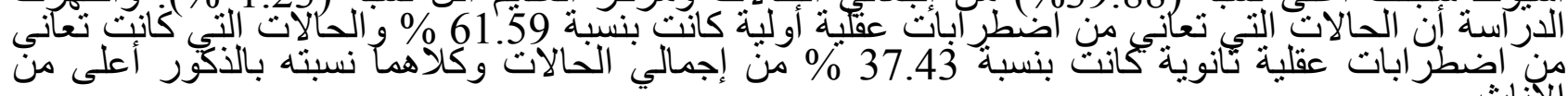
و أظهرت الدراسة أبضا أن معظم المشكلات التي تصاحب حالات الاضطر ابات العقلية و التي من أجلها

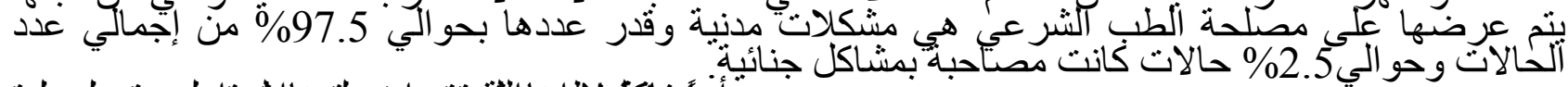

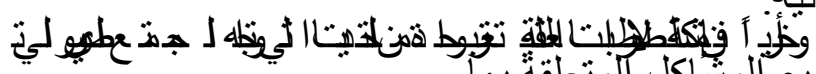

يجب أن تتضافر جميع الجهود للحد منها ومعالجة وحل جميع المشنّاكل المتنعلقةً بها.

1 ${ }^{1}$ 